\title{
Estimation of paddy field dam effect on flood mitigation focusing on Suse region of Hyogo, Japan
}

\author{
Kenichiro Kobayashi ${ }^{1,2}$, Yasunori Kono ${ }^{2}$, Takao Kimura ${ }^{3}$ and Haruya Tanakamaru ${ }^{4}$ \\ ${ }^{\prime}$ Research Center for Urban Safety and Security, Kobe University, Japan \\ ${ }^{2}$ Department of Civil Engineering, Graduate School of Engineering, Kobe University, Japan \\ ${ }^{3}$ Organization for Making a Beautiful Suse Village, Japan \\ ${ }^{4}$ Graduate School of Agricultural Science, Kobe University, Japan
}

\begin{abstract}
:
Recently, Hyogo Prefecture in Japan has expanded its paddy field dam activity within the prefecture using wood weir plates. A wood weir plate was placed at the drainage outlet of a paddy field to limit drainage from the field, thus enabling the paddy fields to store rainwater to a certain extent. As the effect on flood mitigation was not appropriately estimated, we carried out a field experiment using a wood weir plate to estimate the weir coefficient, which determines the drainage discharge from the paddy according to the water depth. Then, using the estimated weir coefficient, we developed a $3,000 \mathrm{~m}^{2}$ paddy field dam model. Thereafter, we applied the model to the Suse region (approximately $33 \mathrm{ha}$ ) considering the 2009 and 2011 rainfall events. It was observed that the paddy field dam has a relatively large effect on reducing the peak discharge (approximately 25.2\% for 2009 and $48.5 \%$ for 2011) within the proximal downstream areas of the paddy dam site. However, the simulation showed that when the rainfall is extreme, as was the case in 2009 , the paddy dam activity may cause erosion of the paddy levee due to the increase in the paddy water depth.
\end{abstract}

KEYWORDS paddy field dam; flood mitigation; field experiment; weir coefficient

\section{INTRODUCTION}

There is a recent report stating that the frequency and intensity of heavy rainfall have been increasing in Japan (Japan Meteorological Agency, 2018). In such situations, both soft (e.g. evacuation plans) and hard countermeasures (e.g. dike or dam construction) for flood disaster management are expected to be taken to reduce flood damage. As complementary countermeasures to the dike or dam construction, paddy field dam projects were implemented in 2002 in Murakami City (former Kamihayashi Village), Niigata, for the first time in Japan (Yoshikawa et al., 2010a). The paddy field dam project of Murakami City included setting a runoff control device (orifice plate; a plate with a circular hole in the center) at the drainage outlet of the paddy field to reduce the outflow from the field.
According to Yoshikawa et al. (2010a), by installing runoff control devices, the main channel discharge of the Fuefuki River (catchment area: $6.24 \mathrm{~km}^{2}$ ) decreased by $26 \%$ in the case of the highest amount of observed rainfall in the region. Other related research in Japan can be found, for example, by Yoshikawa et al. (2010b), Miyazu et al. (2020), and Tanakamaru et al. (2020). In contrast, Oishi et al. (2019) evaluated paddy field dam activity in Nara Prefecture, Japan, using the contingent valuation method. They concluded that the annual willingness to pay per household was estimated at a median value of 2,200 JPY to 3,000 JPY. Following the activity in Niigata Prefecture, Hyogo Prefectural Government in Japan started to distribute wooden weir plates (a rectangular plate with a rectangular cutout on the side) in 2013 to farmers and encouraged them to set up wooden weir plates to increase the flood retention capacities of the paddy fields.

Kim et al. (2011) mentioned that the combined paddy fields in Korea could store 18 times more rainwater than the Soyang Dam, the largest dam in Korea. Hao et al. (2015) reported that urbanization drastically altered the water balance in paddy fields in China. According to their report, the streamflow increased by $58 \%$ and evapotranspiration decreased by $23 \%$ during $1986-2013$ as a result of a three-fold increase in urban areas and a $27 \%$ reduction in rice paddy fields. Sujono (2010) estimated the flood reduction capacity of experimental paddy fields for Indonesia, concluding that more than $40 \%$ of the rainfall could be stored in an experimental paddy field. Likewise, the case of Taiwan was presented by Wu et al. (2001).

From these studies, we can recognize that the paddy field dam has an effect on reducing the peak flow, particularly at the proximal downstream areas, and researchers found some benefits from the activities. Based on these considerations, this research attempted to estimate the flood mitigation effect of the Hyogo-style paddy field by conducting field experiments and numerical simulations of the paddy field and district under the activity.

The remainder of this paper proceeds as follows. Section 2 presents a field experiment at Suse, Hyogo. Section 3 describes the development of a numerical model for paddy compartments. Section 4 describes the development of the numerical model for the actual paddy field in the Suse 
district, Hyogo. Section 5 presents the conclusions and describes the scope of this study.

\section{FIELD EXPERIMENT AT SUSE}

This section presents the results of a field experiment conducted at Suse. The location of the Chikusagawa River catchment in the Kinki region, Japan, is shown in Figure 1a. Figure $1 \mathrm{~b}$ shows the enlarged Chikusagawa River catchment. Figure 1c shows the paddy field at Suse in the Chikusagawa River catchment. Figure 1d shows the enlarged shape of the paddy field. Suse is located in the western part of Hyogo Prefecture and near the main stream of the Chikusagawa River. The field experiment was carried out at Suse, where the actual drainage processes from the paddy fields were observed, and the weir coefficient was estimated using the observation data. In the field experiment, an actual wooden weir plate was used. The wooden weir plate used at Suse is shown in the upper panel of Figure 2. The lower panel in Figure 2 shows a schematic diagram with these dimensions: the plate had a height of $10 \mathrm{~cm}$ and the cutout was $5 \mathrm{~cm}$. The figure also shows the three possible water levels. When the water level is 1 or 3
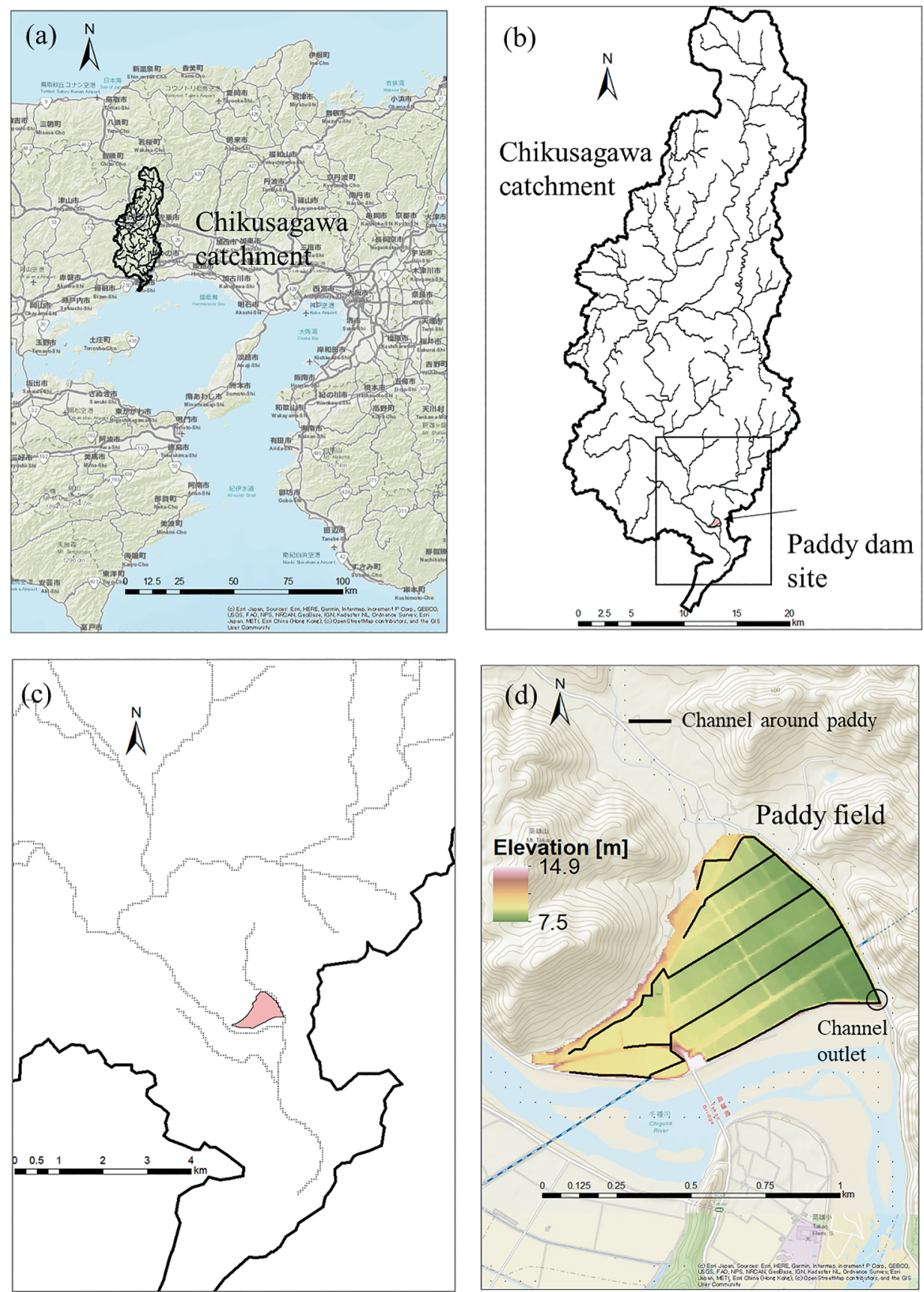

Figure 1. (a) Location of Chikusagawa River catchment in Kinki region Japan (b) Chikusagawa River catchment, (c) Suse in Chikusagawa River catchment, and (d) Shape of the paddy field in Suse (backgrounds are the maps in ArcGIS) 


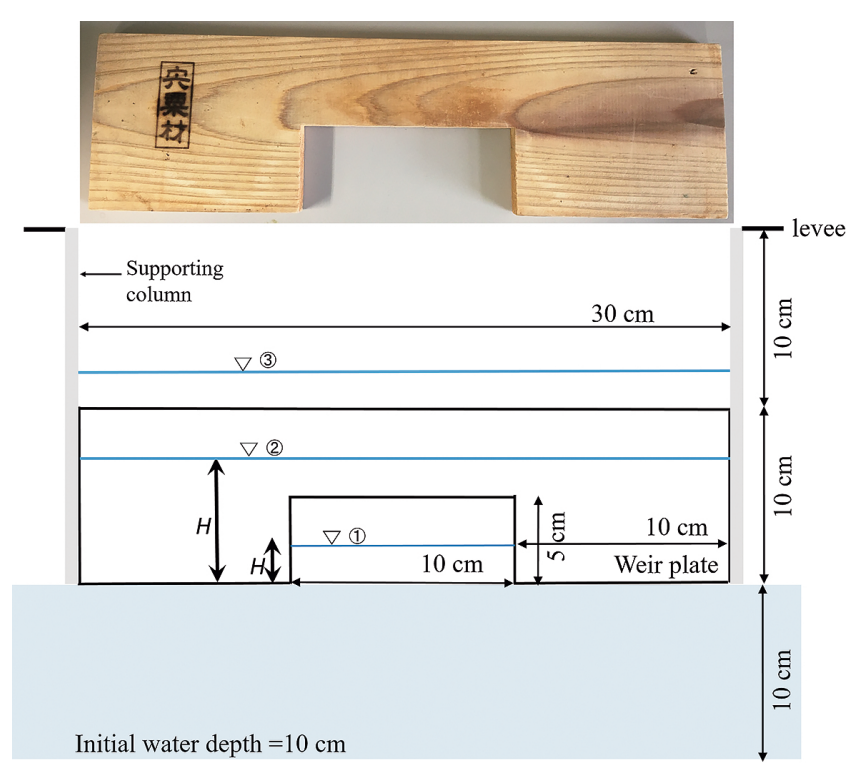

Figure 2. Photo (upper) and schematic diagram (lower) of the wood weir plate

in the figure, a weir formula (Equation (1)) with the dimensions of the rectangular cutout hole or the full plate width is used. Likewise, when the level is 2 , an orifice formula (Equation (2)) is used.

$$
\begin{aligned}
& Q=\frac{2}{3} C_{w} B_{w} \sqrt{2 g H^{3}} \\
& Q=C_{0} A_{c} \sqrt{2 g H},
\end{aligned}
$$

where $Q$ is the discharge in $\left(\mathrm{m}^{3} / \mathrm{s}\right), C_{w}$ and $C_{0}$ are the weir and orifice discharge coefficients, respectively, $B_{w}$ is the width of the weir plate cutout or full weir plate in $(\mathrm{m}), A_{c}$ is the flow area of the cutout of the wood plate in $\left(\mathrm{m}^{2}\right), H$ is the water depth in $(\mathrm{m})$, and $g$ is the acceleration due to gravity in $\left(\mathrm{m}^{2} / \mathrm{s}\right)$.

The weir formula by Japan Society of Civil Engineers (JSCE, 1999), which is often used for the estimation of the weir coefficient, was outside the application range for the wooden plate and therefore a field experiment was carried out.

The irrigation cycle of the region is as follows:

(1) Around June 10: Transplanting rice. The water level was approximately $2-3 \mathrm{~cm}$ in this period.

(2) Between July 1 and September 30: Paddy Dam period. The water level was approximately $10 \mathrm{~cm}$ during this period.

(3) Around October 10: Rice reaping.

Thus, the period of paddy dam activity in the region was only three months.

\section{Field experiment}

This section presents the results of the field experiment carried out in Suse in an actual paddy field during the paddy dam season. Two compartments of the paddy field were used, as shown in Figure 3a. In the field experiment, the paddy field water was drained in one compartment

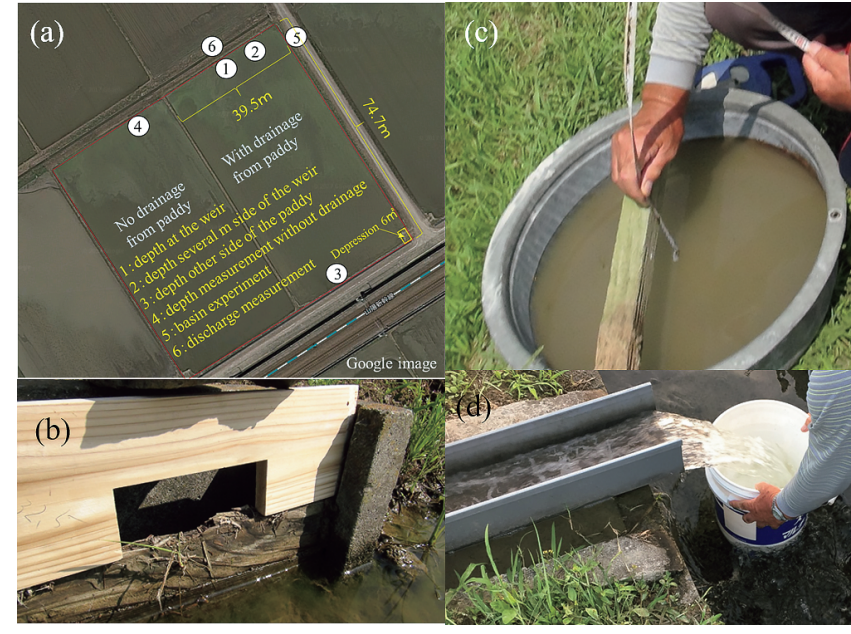

Figure 3. (a) Paddy field used for the field experiment and the locations for the measurements, (b) Snapshot of the weir plate setting, (c) Snapshot of the water depth measurement without infiltration, and (d) Snapshot of the discharge measurement with a bucket

(right in Figure 3a), while it was not drained in the other (left in Figure 3a).

The primary purpose of the experiment was to measure the decrease in the water depth and the amount of discharge from the drainage of the paddy field to estimate the discharge coefficient in the field. The area of the paddy field is 2,950.65 $\mathrm{m}^{2}$.

\section{Methodology}

The field experiment was carried out on July 13-14, 2017, for two days. On the first day, the weir plate was set at 1 in Figure 3a, as shown in Figure $3 b$ in the right paddy field. The paddy field was first filled with water from the bottom of the field to the top of the weir plate; then, the water was drained. The experiment on the first day was carried out between 8:50 and 20:50 for $12 \mathrm{~h}$. Note that the direction of the weir plate was only concave downward since Hyogo Prefectural government recommends farmers to set up the plate in that direction. On the second day, the weir plate was not set in the right-side paddy field. The measurements were carried out between 9:00 and 16:00 for $7 \mathrm{~h}$. The overall measurement procedures were the same on the first and second days. In the left paddy field, the measurement was carried out for two days without draining the water.

The following parameters were measured every hour.

Water depth in the paddy

The measurements of the water depths with drainage (with or without the weir plate) in the right paddy field were carried out at locations 1, 2, and 3 in Figure 3a. In the left non-drained field, the measurement was performed at 4 in Figure 4a for two days. Additionally, the water depth without infiltration was estimated by measuring the water depth in the basin at 5 in Figure 3a, as shown in Figure 3c. 

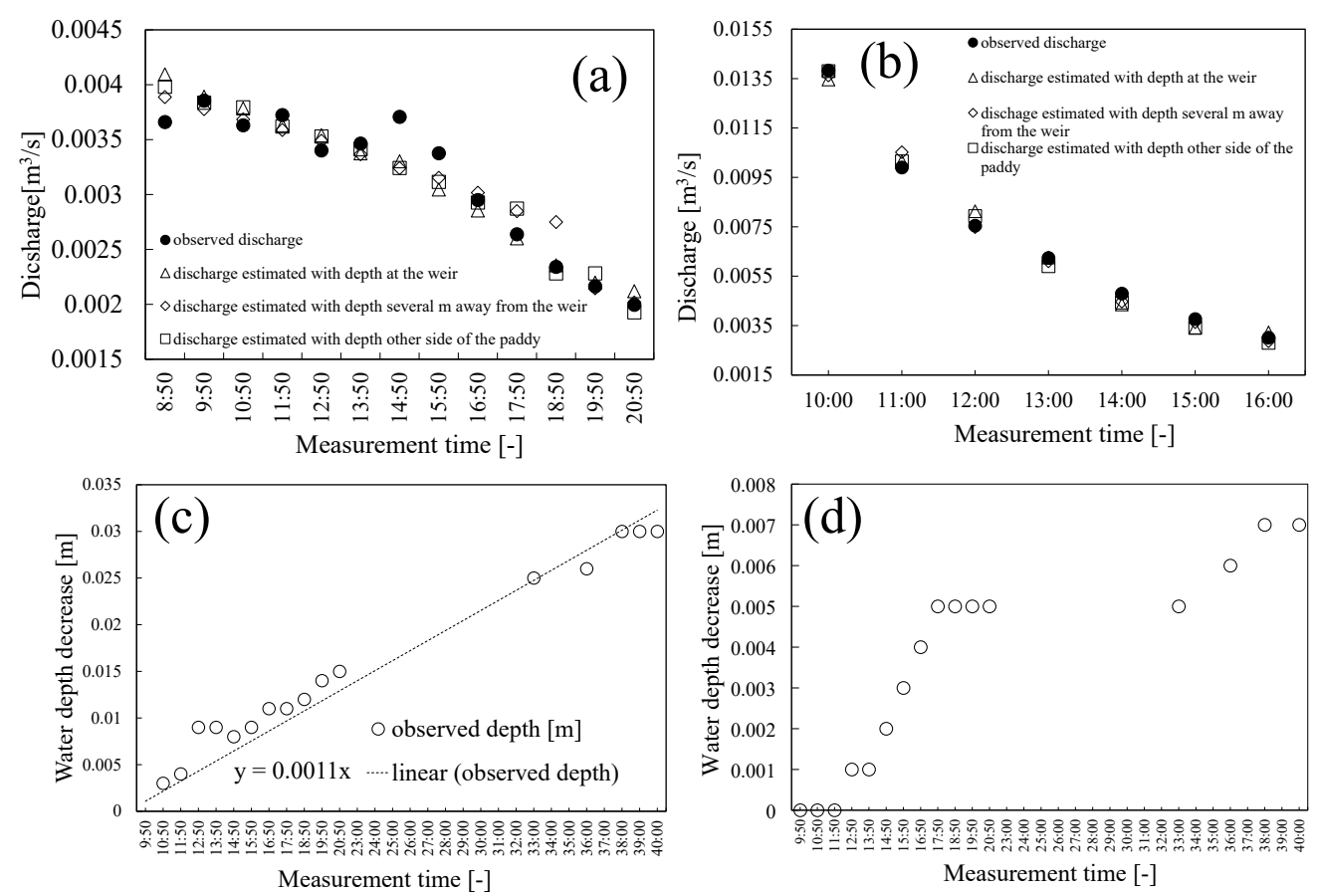

Figure 4. (a) Measured and calculated discharges by the formula when the weir plate was set, (b) When the weir plate was not set, (c) Decrease in the water depth in the paddy field without drainage, and (d) Decrease in the water depth in the basin

\section{Discharge measurement from the paddy field}

The discharge measurements were carried out at 6 (Figure 3a). A bucket was used to collect the water drained from the paddy (Figure 3d), and the time until the bucket was filled was measured five times, and the discharge was calculated by taking the average.

\section{Estimation of the discharge coefficient}

The discharge coefficient was estimated using Equations (1) and (2). When the weir plate was concave downward, the orifice formula (Equation (2)) was used between 0.05 and $0.1 \mathrm{~m}$ of the water depth, and the weir formula (Equation (1)) was used below $0.05 \mathrm{~m}$ of the water depth. When the weir plate was not set, the weir formula (Equation (1)) was used with $0.3 \mathrm{~m}$, which is the width of the drainage outlet itself without the weir (see Figure 3b).

\section{Field experiment result}

The observed and calculated discharges by the formulas in the right paddy field are shown in Figures $4 a$ and $4 b$. Figure 4a shows the result with the weir plate, while Figure $4 \mathrm{~b}$ shows the result without the plate. Note that the depth at the weir indicates the depth at 1 , depth several meters away from the weir is at 2, depth at the other side of the paddy is at 3 . The drainage discharge was higher when the plate was not set. The estimated discharge coefficients are summarized in Table SI.

The time series of the water depth in the left paddy field without drainage is shown in Figure 4c. The total decrease in the water depth was $0.03 \mathrm{~m}$ for the two days. In other words, the depth decreased by $3 \mathrm{~cm}$ because of evapotranspiration and infiltration. The changes in the water depth in the basin are shown in Figure 4d. As a result, the decrease in water depth in the basin by evaporation without infiltra- tion was $0.007 \mathrm{~m}$.

From the results of the field experiment, we can draw the following conclusions: In the field experiment, the coefficient with the plate concave downward was 0.47 for the orifice and 0.69 for the weir. Without the plate, the discharge coefficient was 0.66 , using the weir formula. The coefficient estimated using the water depth several meters from the weir is used in the following numerical modeling because the water depth close to the weir fluctuates modestly due to waves and the water depth on the other side of the weir cannot be used.

\section{NUMERICAL MODEL OF A PADDY FIELD COMPARTMENT}

As a next step, a numerical model to simulate the water depth in a paddy compartment with a weir wood plate was constructed. The conditions of the modeling are as follows: (1) the weir was set as concave downwards, (2) the orifice formula was used at a water depth $H>0.05 \mathrm{~m}$ and $H<$ $0.1 \mathrm{~m}$ (water level 2 in Figure 2, lower panel) over the initial water depth $0.1 \mathrm{~m}$, and the weir formula was used at $H$ $<0.05 \mathrm{~m}$ (water level 1 in Figure 2, lower panel). When the water depth was $H>0.1 \mathrm{~m}$ (water level 3 in Figure 2, lower panel), the weir formula with the full width of the wood weir plate and orifice formula were used. On the other hand, the weir formula was used when the weir plate was not set (same as 3 in Figure 2, lower panel). The initial water depth of the paddy was $0.1 \mathrm{~m}$. The area of the paddy was $2,950.65 \mathrm{~m}^{2}$, which is the average size of a paddy field in Japan. The purpose of this simulation was to reproduce the observation and additionally to investigate if the inundated water around $H=0.1 \mathrm{~m}$ added to the initial depth of 
$0.1 \mathrm{~m}$ in the paddy negatively affects the growth of the paddy. The equations are as follows:

(a) Over the weir plate (3 in Figure 2, lower panel)

Water depth $H>0.1 \mathrm{~m}$ (Weir + Orifice)

$$
\begin{aligned}
& H_{i+1}=H_{i} \\
& -\left(\frac{2}{3} C_{w p} B_{w p} \frac{d t}{A_{\text {paddy }}} \sqrt{2 g\left(H_{i}-0.1\right)^{3}}+C_{o} A_{c} \frac{d t}{A_{\text {paddy }}} \sqrt{2 g H_{i}}\right) \\
& + \text { rain } \cdot d t-S_{i} \cdot d t
\end{aligned}
$$

(b) Water depth $H>0.05 \mathrm{~m}$ and $H<0.1 \mathrm{~m}$ (Orifice) (2 in Figure 2, lower panel)

$$
H_{i+1}=H_{i}-\left(C_{o} A_{c} \frac{d t}{A_{\text {paddy }}} \sqrt{2 g H_{i}}\right)+\text { rain } \cdot d t-S_{i} \cdot d t
$$

(c) Water depth $H<0.05 \mathrm{~m}$ (Weir) (1 in Figure 2 lower panel)

$$
H_{i+1}=H_{i}-\left(\frac{2}{3} C_{w c} B_{w c} \frac{d t}{A_{\text {paddy }}} \sqrt{2 g H_{i}^{3}}\right)+\operatorname{rain} \cdot d t-S_{i} \cdot d t
$$

(d) Without weir plate (Weir) (same as 3 in Figure 2, lower panel)

$$
H_{i+1}=H_{i}-\left(\frac{2}{3} C_{w p} B_{w p} \frac{d t}{A_{p a d d y}} \sqrt{2 g H_{i}^{3}}\right)+\operatorname{rain} \cdot d t-S_{i} \cdot d t
$$

where $H_{i}$ is the water depth (m), $C_{o}$ is the discharge coefficient of the orifice formula, $C_{w p}$ is the discharge coefficient of the weir formula with full wood plate width (this is the same when the plate was not set), $C_{w c}$ is the discharge coefficient with the wood plate cutout width, $B_{w p}$ is the width of the full weir in (m), $B_{w c}$ is the width of the cutout of the weir in (m), $A_{c}$ is the area of the cutout of the plate in $\left(\mathrm{m}^{2}\right)$, $A_{\text {paddy }}$ is the area of the paddy field in $\left(\mathrm{m}^{2}\right), S_{i}$ is the average decrease in water depth per hour due to infiltration in $(\mathrm{m} / \mathrm{s})$, rain is the rainfall in $(\mathrm{m} / \mathrm{s})$ though it is set to zero in the simulation of this section, and $d t$ is the interval of the time step in (s).

The simulation results are shown in Figure 5. The simulated water depths agree with the observed data. With the weir plate, the water depth $H$ after $24 \mathrm{~h}$ decreased to $0.013 \mathrm{~m}$, and the water depth became zero after $35 \mathrm{~h}$. In the simulation, the maximum water depth in the paddy was

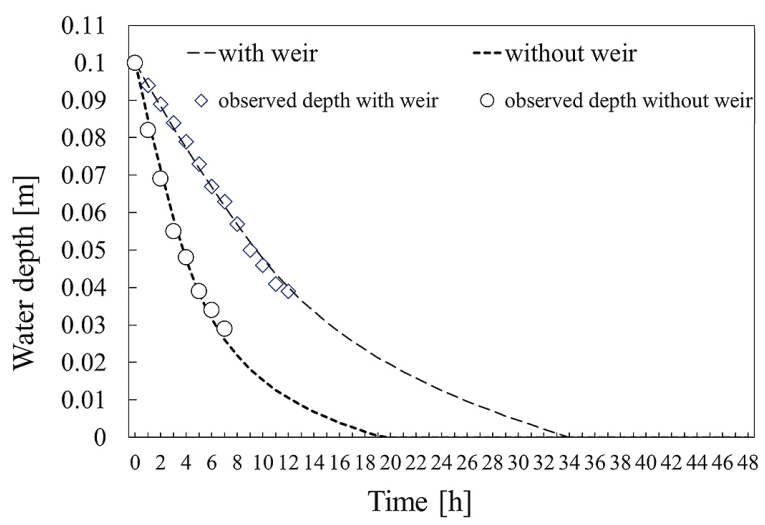

Figure 5. Change in the water depth by observation and simulation for a paddy compartment (Area: $2936.75 \mathrm{~m}^{2}$ )
$0.1 \mathrm{~m}+$ initial water depth of $0.1 \mathrm{~m}$, and the water was drained sufficiently after $24 \mathrm{~h}$; thus, the negative effect due to the application of the paddy dam on the growth of the paddy is negligible. Without the weir plate, the water drains faster. In this case, the simulated water depth also agrees well with the observations.

\section{FLOOD MITIGATION EFFECT OF THE PADDY FIELD DAM IN SUSE}

A numerical model of a paddy field dam for the Suse region was developed. Figures $1 \mathrm{c}$ and 1d, as previously introduced, show the area map of the Suse region. The numerical model consists of the paddy field dam module of a compartment, which is the same as the model introduced in the previous section, and a module of a 1D drainage channel network surrounding the paddy by a dynamic wave model (see Channel around paddy in Figure 1d). The 1D dynamic wave model is as follows:

Continuity equation:

$$
\frac{\partial A}{\partial t}+\frac{\partial Q}{\partial x}=q_{i n}
$$

Momentum Equation:

$$
\frac{1}{g} \frac{\partial u}{\partial t}+\frac{u}{g} \frac{\partial u}{\partial x}+\frac{\partial h}{\partial x}=s_{0}-\frac{n^{2} u|u|}{R^{4 / 3}}
$$

where $A$ is the river cross-section in $\left(\mathrm{m}^{2}\right), Q$ is the river discharge in $\left(\mathrm{m}^{3} / \mathrm{s}\right), q_{\text {in }}$ is the lateral inflow per unit length from the orifice/weir (positive value) in $\left(\mathrm{m}^{2} / \mathrm{s}\right), g$ is the acceleration due to gravity in $\left(\mathrm{m} / \mathrm{s}^{2}\right), u=Q / A$ is the average flow velocity over the cross-section in $(\mathrm{m} / \mathrm{s}), s_{0}$ is the slope gradient, $n$ is the Manning roughness coefficient, and $R$ is the hydraulic radius in $(\mathrm{m})$. The flux difference splitting method was used for numerical discretization.

The paddy field module and drainage channel network module are connected by the orifice/weir formula with the weir wood plate in the previous sections, assuming that the plate is placed concave downward. The inflow from the paddy to the channel was treated as the lateral inflow for the 1D dynamic wave model. There are no inflows to the paddy field from outside of Suse region.

The number of computational grids for the entire 1D channel network was 5,837 with a resolution of $1 \mathrm{~m}$. The total number of paddy fields in Suse is 145 , and the total area is $327,216 \mathrm{~m}^{2}$. The setup ratio of the wood weir plate was $100 \%$. Thus, the area information of 145 paddies was collected and given to the Suse model as input.

The hyetographs of the rainfall intensity of Sayo (JMA) and Sayo (Hyogo Prefecture) during Typhoon No. 21 in August 2009 and Typhoon No. 12 in August 2011 were given to the Suse model, as shown in Figure 6 (upper-left and -right panels). The model validity was checked with mass conservation, as there were no observed data available. Figure 6, middle-left and -right panels show the comparison of the discharges at the downstream end with and without the weir plate for both rainfall events. The figure also shows these differences. The difference in the discharges at the peak was $0.968 \mathrm{~m}^{3} / \mathrm{s}$ and $0.488 \mathrm{~m}^{3} / \mathrm{s}$ for the 2009 and 2011 rainfall events, respectively. The reduction in the peak discharge by the weir was $25.2 \%$ and $48.5 \%$ of 

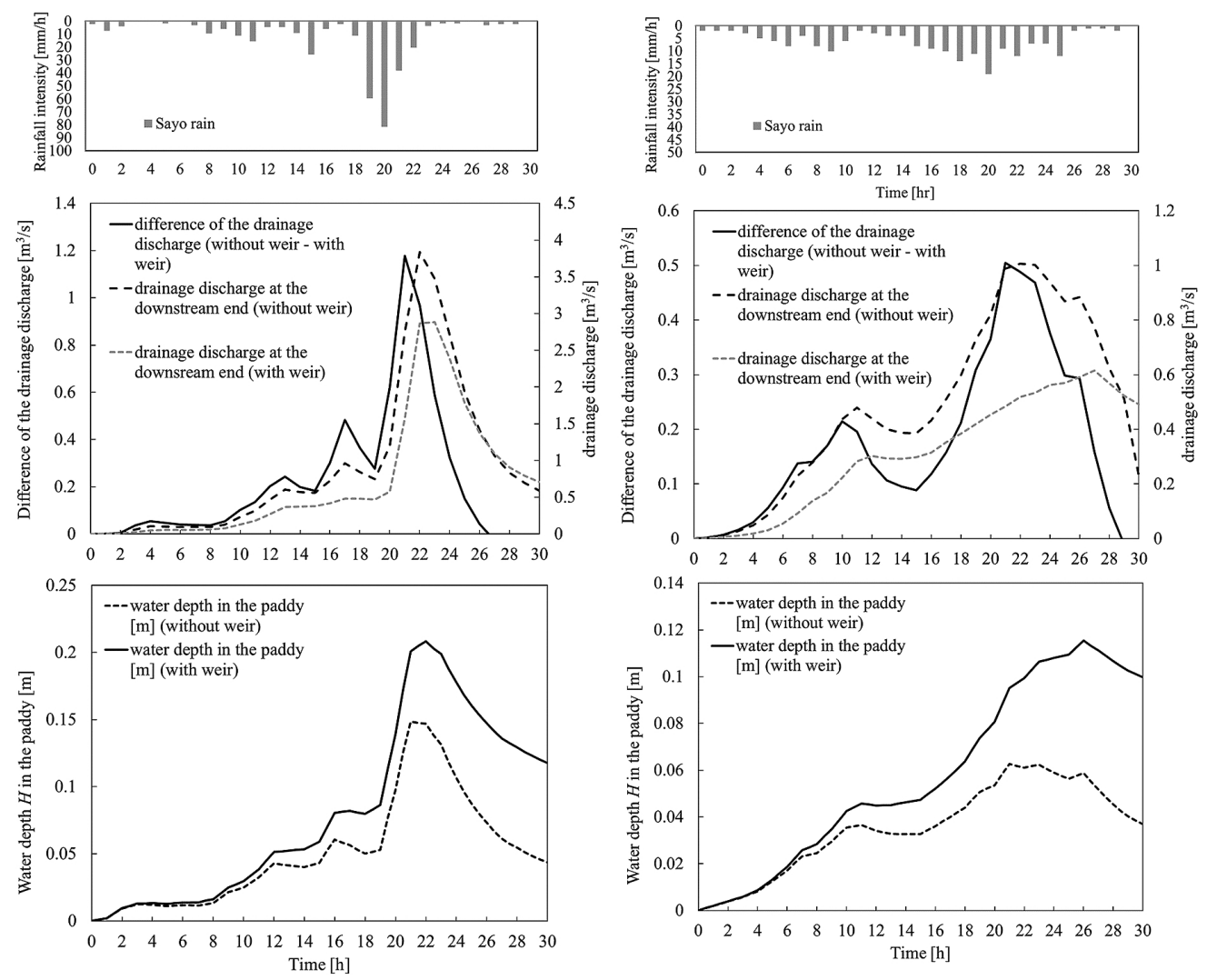

Figure 6. Hourly rainfall hyetograph of Typhoon No. 21 August 2009 (upper left) and Typhoon No. 12 August 2011 (upper right), drainage discharge hydrograph with/without the weir for 2009 (middle left) and 2011 (middle right) rainfalls and paddy water depth for 2009 (lower left) and 2011 (lower right)

the discharge without the weir for 2009 and 2011 rainfall, respectively. However, the lower left and right panels in Figure 6 show the water level in a paddy of $3,000 \mathrm{~m}^{2}$ for the 2009 and 2011 rainfall events. As shown, the water depth $H$ for 2009 rainfall attained $0.21 \mathrm{~m}+0.10 \mathrm{~m}=$ $0.31 \mathrm{~m}$ with the weir and $0.15 \mathrm{~m}+0.10 \mathrm{~m}=0.25 \mathrm{~m}$ without the weir. We assumed the level of the levee is $0.3 \mathrm{~m}$. Thus, the water level with the weir is beyond the level of the levee. In other words, it is not recommended to use the weir plate for the extreme 2009 flood case because erosion of the levee may occur. On the other hand, the water depth $H$ for 2011 rainfall is $0.12 \mathrm{~m}+0.10 \mathrm{~m}=0.22 \mathrm{~m}$ with the weir and $0.067 \mathrm{~m}+0.10 \mathrm{~m}=0.167 \mathrm{~m}$ without the weir. The water level does not exceed the levee height in this case, although overtopping above the wood weir plate occurred when the weir was set. The peak time was delayed for $1 \mathrm{~h}$ in the 2009 case, whereas it was delayed for $5 \mathrm{~h}$ in the 2011 case. Thus, the wood weir plate not only reduces the peak discharge but also delays the timing of the peak discharge.

\section{CONCLUSIONS}

This paper presents a study for the estimation of the paddy field dam effect, focusing on the Suse region of Hyogo Prefecture, Japan. First, a field experiment was conducted to estimate the orifice/weir coefficients of the wood plate. Then, the coefficients of the field experiment were used for the numerical model for a compartment of the paddy field, and then for the Suse region consisting of 145 paddy compartments.

The discharge and water level of a paddy compartment analysis of approximately $3,000 \mathrm{~m}^{2}$ by field experiment and the newly constructed numerical model were similar; thus, the model validity was confirmed. Moreover, the result of the numerical model shows that, with the weir plate, the water depth $H$ above $0.1 \mathrm{~m}$ (= initial water ponding) after $24 \mathrm{~h}$ starting from $H=0.1 \mathrm{~m}$ (total $0.2 \mathrm{~m}$ ) decreased to $H=$ $0.013 \mathrm{~m}$, and the water depth $H$ becomes zero after $35 \mathrm{~h}$. Thus, the negative effects of the paddy field dam on paddy growth are negligible.

Then, the paddy compartment model was expanded for the Suse region of approximately 33 ha. The Suse numerical model consists of 145 paddy compartment models and a drainage network model using a 1D dynamic wave equation. A hyetograph of the rainfall intensity of Sayo at Typhoons in August 2009 and 2011 was provided to the Suse model. As a result, the reduction in the peak discharge by the weir was $48.5 \%$ and $25.2 \%$ of the discharge without the weir for the 2011 and 2009 rainfall events, respectively. However, in the 2009 case, the simulation shows that the overtopping of the paddy water over the levee may occur; thus, the setup of the wood plate was not recommended. Overall, it is recognized that the weir has a relatively large effect on flood mitigation within the proximal downstream areas of the paddy field of the Suse region for middle-scale 
rainfall events. Likewise, it has a function to delay the timing of peak discharge. However, attention should be paid when rainfall is extremely large because there is a risk of levee erosion in such cases.

\section{ACKNOWLEDGMENTS}

Ako-City supported the paddy field dam pilot study by the "Organization for Making a Beautiful Suse Village (free translation)". Similarly, we received useful advice from Hyogo Prefecture. We would also like to thank them for this study.

\section{SUPPLEMENTS}

Table SI. Weir coefficient estimations

\section{REFERENCES}

Hao L, Sun G, Liu Y, Wan J, Qin M, Qian H, Liu C, Zheng J, John R, Fan P, Chen J. 2015. Urbanization dramatically altered the water balances of a paddy field-dominated basin in southern China. Hydrology and Earth System Sciences 19: 3319-3331. DOI: 10.5194/hess-19-3319-2015.

Japan Meteorological Agency (JMA). 2018. Climate change monitoring report 2017. https://www.jma.go.jp/jma/en/NMHS/ ccmr/ccmr2017_high.pdf. Last access January 22, 2021.

Japan Society for Civil Engineers. 1999. Suiri-Koshiki-shu (Heisei 11 nendoban).

Kim JO, Lee SH, Jang KS. 2011. Efforts to improve biodiversity in paddy field ecosystem of South Korea. Reintroduction 1: 25-30. http://www.stork.u-hyogo.ac.jp/downloads/journal/ 01_05.pdf. Last access January 22, 2021.

Miyazu S, Matsushita T, Iwamura Y, Yoshikawa N. 2020. Study on limit of flood mitigation effect of paddy field dam. Journal of Japan Society of Civil Engineers, Ser. B1 (Hydraulic Engineering) 76: I_805-I_810 (in Japanese).

Oishi T, Nakano R, Matsuno Y. 2019. Perception and valuation of Paddy Field Dam functions by rural communities: a CVM approach. Paddy and Water Environment 17: 383-390. DOI: 10.1007/s10333-019-00733-2.

Sujono J. 2010. Flood reduction function of paddy rice fields under different water saving irrigation techniques. Journal of Water Resource and Protection 2: 555-559. DOI: 10.4236/ jwarp.2010.26063.

Tanakamaru H, Yarimoto K, Tada A. 2020. Estimation and evaluation of rainwater storage capacity obtained by water release from irrigation ponds. Water, Land and Environmental Engineering 88: 733-736 (in Japanese).

Wu RS, Sue WR, Chien CB, Chen CH, Chang JS, Lin KM. 2001. A simulation model for investigating the effects of rice paddy fields on the runoff system. Mathematical and Computer Modelling 33: 649-658. DOI: 10.1016/S08957177(00)00269-7.

Yoshikawa N, Nagao N, Misawa S. 2010a. Evaluation of the flood mitigation effect of a Paddy Field Dam project. Agricultural Water Management 97: 259-270. DOI: 10.1016/j.agwat. 2009.09.017.

Yoshikawa N, Miyazu S, Koide H, Misawa S, Yasuda H. 2010 b. Evaluation of flood mitigation effect of a paddy field dam in an unimproved paddy field area. Advances in River Engineering 16: 507-512 (in Japanese). 